\title{
Penambahan Natrium Bikarbonat 8,4\% pada Lidokain 2\% untuk Mengurangi Nyeri Saat Infiltrasi Anestetik Lokal
}

\author{
Doni Arief Rahmansyah, ${ }^{1}$ Abdul Muthalib Nawawi, ${ }^{2}$ Erwin Pradian $^{2}$ \\ ${ }^{1}$ Instalasi Intensive Care Unit (ICU) Badan Layanan Umum Daerah Rumah Sakit Umum Kota Banjar, \\ ${ }^{2}$ Departemen Anestesiologi dan Terapi intensif \\ Fakultas Kedokteran Universitas Padjadjaran/Rumah Sakit Dr. Hasan Sadikin Bandung
}

\begin{abstract}
Abstrak
Infiltrasi anestesi lokal di daerah penyuntikan jarum epidural menggunakan lidokain menimbulkan nyeri. Penelitian ini bertujuan untuk mengetahui keefektifan penambahan natrium bikarbonat 8,4\% pada lidokain $\mathrm{HCl}$ 2\% dengan perbandingan 1:10 untuk mengurangi nyeri saat infiltrasi. Penelitian dilakukan pada bulan Juni hingga Juli 2013 di Rumah Sakit Umum Pusat Dr. Hasan Sadikin Bandung. Penelitian dilakukan dengan uji klinis acak tersamar ganda pada 44 pasien yang menjalani operasi dengan teknik anestesi epidural. Subjek dibagi 2 kelompok, kelompok eksperimen (LB) mendapatkan infiltrasi lidokain $\mathrm{HCl} 2 \%$ alkalin dengan menambahkan natrium bikarbonat 8,4\% dengan perbandingan 1:10, kelompok kontrol (L) mendapatkan lidokain $\mathrm{HCl} 2 \%$. Pada kedua kelompok dinilai numeric rating scale (NRS) saat infiltrasi lidokain $\mathrm{HCl} 2 \%$. Hasil penelitian diuji dengan uji chi-kuadrat, uji-t, dan Uji Mann-Whitney, tingkat kepercayaan 95\% dan kekuatan uji 94\%, dianggap bermakna bila nilai $p<0,05$. Analisis statistik menunjukkan perbedaan bermakna nilai median NRS pada kelompok eksperimen dengan kelompok kontrol saat infiltrasi anestesi lokal (5 vs 3), dengan nilai rentang (3-6 vs 1-4) dengan nilai $\mathrm{p}<0,05$. Simpulan penelitian ini adalah alkalinisasi lidokain $\mathrm{HCl} 2 \%$ dengan penambahan natrium bikarbonat 8,4\% dengan perbandingan 1:10 mempunyai efek mengurangi nilai NRS.
\end{abstract}

Kata kunci: Alkalinisasi, lidokain $\mathrm{HCl}$ 2\%, natrium bikarbonat 8,4\%

\section{Addition of 8.4\% Sodium Bicarbonate to 2\% Lidocaine in Reducing Pain During Local Anaesthetic Infiltration}

\begin{abstract}
Local anesthetic infiltration in the area of epidural injections using lidocaine can cause pain. This research was done in June-July 2013, in Dr. Hasan Sadikin Hospital, to determine the effectiveness of adding 8.4\% sodium bicarbonate to lidocaine $\mathrm{HCl} 2 \%$ with 1:10 ratio. This was a double-blind randomized control study involving 44 patients undergoing surgery with epidural techniques. Subjects were divided into two groups, the experimental group (LB) was given $2 \%$ lidocaine $\mathrm{HCl}$ with sodium bicarbonate $8.4 \%$ 1:10 ratio as a local anestetich while the control group (L) was given lidocaine $2 \%$. Numeric rating scale (NRS) was assessed during infiltration. Data was analyzed using chi-squere test, t-test and Mann-Whitney Test, with $95 \%$ confidence level and $94 \%$ strength tes and considered significant if $p<0.05$. Statistical anaylsis showed a significant difrerence in median of NRS in the experiment compared to control group during local anaesthetic infiltration (5 versus 3 ), with range of 3-6 versus $1-4$ with $p>0.05$. In conclusion, alkalinization of $2 \%$ lidocaine $\mathrm{HCl}$ by addition of $8.4 \%$ sodium bicarbonate with $1: 10$ ratio has an effect in reducing NRS.
\end{abstract}

Key words: Alkalinization, lidocaine $\mathrm{HCl} 2 \%$, sodium bicarbonate $8.4 \%$

Korespondensi: Doni Arief Rahmansyah, dr., SpAn, Instalasi Intensive Care Unit (ICU) Badan Layanan Umum Daerah Rumah Sakit Umum Kota Banjar, Jl. Rumah Sakit No. 5, Banjar, 46322, Tlp/Faksmili 0265-741032/0265-744730, Mobile 8122393954,Email ratnasari_8@yahoo.co.id 


\section{Pendahuluan}

Seorang dokter anestesi bertugas memberikan pelayanan yang dapat memfasilitasi tindakan pembedahan, yang diharapkan tidak hanya aman namun dapat memberikan rasa nyaman pada pasien saat sebelum pembedahan, selama pembedahan, dan juga setelah pembedahan. ${ }^{1,2}$ Teknik anestesia epidural merupakan salah satu anestesia regional yang dapat dilakukan untuk memfasilitasi tindakan pembedahan dan memberikan keuntungan dalam pengelolaan nyeri pascabedah. Salah satu hal penting yang mengganggu kenyamanan pasien adalah nyeri saat dilakukan penusukan jarum epidural. Hal tersebut diatasi dengan memberikan anestesi infiltrasi di daerah penyuntikan jarum epidural dengan menggunakan obat anestesi lokal. ${ }^{3}$

Namun, penggunaan anestetik lokal yang diberikan melalui infiltrasi untuk mengurangi nyeri saat penusukan jarum epidural tersebut ternyata juga dapat menimbulkan rasa nyeri. Hasil penelitian terdahulu telah membuktikan bahwa saat dilakukan infiltrasi obat anestesi lokal lidokain $\mathrm{HCl} 1 \%$ akan menghasilkan nilai visual analogue scale (VAS) 7. Penelitian lain menunjukkan $87 \%$ pasien merasakan nyeri akibat infiltrasi anestetik lokal. Obat anestesi lokal yang bersifat asam menyebabkan iritasi pada jaringan, sehingga menimbulkan sensasi panas dan juga rasa nyeri. Pada nilai $\mathrm{pH}$ yang rendah, fraksi nonionisasi anestetik lokal juga akan rendah sehingga mula kerja anestesi lokal lebih lama. Selain pH obat, ukuran jarum, suhu, kecepatan penyuntikan obat anestesia lokal juga memengaruhi nyeri yang ditimbulkan pada saat infiltrasi anestesi lokal., ${ }^{4,5}$

Infiltrasi obat anestesi lokal yang dilakukan sebelum insersi jarum epidural juga belum begitu efektif untuk mengurangi nyeri sewaktu insersi jarum epidural. Strout mendapatkan nilai VAS 4 pada saat insersi jarum epidural, begitu pula Nakayama dkk. ${ }^{7}$ yang mendapatkan nilai VAS 4-5. Pada kedua penelitian tersebut menggunakan obat anestesi lokal lidokain $\mathrm{HCl}$ $1 \%$. Hal itu berdampak pada timbulnya rasa tidak nyaman sebelum tindakan pembedahan dilaksanakan. ${ }^{6,7}$

Pada penelitian sebelumnya menunjukkan bahwa $68 \%$ pasien merasakan lebih nyeri saat infiltrasi anestesi lokal menggunakan lidokain $\mathrm{HCl} 1 \%$ apabila dibandingkan dengan lidokain $1 \%$ yang dialkalinisasi dengan menambahkan natrium bikarbonat $8,4 \%$ menggunakan rasio 1:10, sedangkan penelitian Nakayama dkk. ${ }^{7}$ menunjukkan $88 \%$ pasien merasakan lebih nyeri saat infiltrasi anestesi lokal menggunakan lidokain $\mathrm{HCl} 1 \%$ dibandingkan dengan lidokain $1 \%$ yang ditambah dengan natrium bikarbonat $8,4 \%$ dengan perbandingan 1:10. Nakayama dkk. ${ }^{7}$ menyatakan juga bahwa alkalinisasi pada lidokain $\mathrm{HCl}$ dengan menambahkan natrium bikarbonat 8,4\% dengan pengenceran 1:10 akan mengubah $\mathrm{pH}$ mendekati $\mathrm{pH}$ jaringan tubuh tanpa ada risiko terjadi presipitasi obat anestesia lokal serta menjadi lebih stabil.

Penelitian sebelumnya, mencoba perlakuan alkalinisasi lidokain $\mathrm{HCl} 2 \%$ mempergunakan pengenceran 1:2 serta 1:5 untuk mengurangi nyeri saat infiltrasi anestetik lokal, ternyata kedua pengenceran tersebuttidakmemberikan hasil yang signifikan dalam mengurangi nyeri pada saat infiltrasi anestesi lokal dibandingkan tanpa alkalinisasi. ${ }^{6,7}$ Penelitian ini bertujuan untuk mengetahui efek penambahan natrium bikarbonat 8,4\% pada lidokain $\mathrm{HCl} 2 \%$ dengan perbandingan 1:10 dalam mengurangi nyeri saat infiltrasi.

\section{Subjek dan Metode}

Metode penelitian yang dipergunakan adalah eksperimental dengan uji acak terkontrol buta ganda (double blind randomized controlled trial). Pemilihan subjek penelitian berdasarkan kriteria inklusi, yaitu pasien yang menjalani operasi elektif dengan anestesia epidural di Rumah Sakit Dr. Hasan Sadikin Bandung pada bulan Juni sampai Juli 2013 dan berusia 18-65 tahun. Kriteria eksklusi, adalah riwayat alergi terhadap lidokain, terdapat luka di tempat infiltrasi dan insersi epidural, nyeri kronik di daerah infiltrasi serta nyeri kanker, terdapat kontraindikasi pemakaian anestesia epidural, pasien dengan nilai Hamilton Anxiety Rating Scale (HARS) $\geq 15$.

Besar sampel ditentukan memakai formula uji hipotesis 2 (dua) rata-rata, dan didapatkan 
jumlah sampel 22 orang untuk tiap kelompok perlakuan. Analisis statistika mempergunakan uji-t, uji chi-kuadrat, dan Uji Mann-Whitney.

Setelah mendapatkan persetujuan atau izin dari Komite Etik Penelitian Kesehatan Fakultas Kedokteran Universitas Padjadjaran/Rumah Sakit Dr. Hasan Sadikin Bandung, dilakukan penjelasan serta diminta persetujuan kepada keluarga/orangtua pasien tentang penelitian yang dilakukan. Pasien dijelaskan tentang tata cara penilaian numeric rating scale (NRS) serta dilakukan penilaian tingkat kecemasan dengan mempergunakan penilaian HARS, kemudian dilakukan randomisasi mempergunakan tabel bilangan random.Subjek dikelompokkan dalam 2 (dua) kelompok perlakuan, yaitu kelompok L untuk kelompok yang mendapatkan lidokain $\mathrm{HCl} 2 \%$ yang ditambahkan $\mathrm{NaCl}$ 0,9\% dengan perbandingan 1:10 serta kelompok LB untuk kelompok yang mendapatkan lidokain $\mathrm{HCl} 2 \%$ ditambah natrium bikarbonat $8,4 \%$ dengan perbandingan 1:10 (lidokain $\mathrm{HCl}$ 2\% 2 mL yang telah ditambahkan natrium bicarbonat $8,4 \%$ $0,2 \mathrm{~mL}$ ). Saat pasien di kamar operasi, dilakukan pemasangan jalur vena dengan kanula vena no. 18, alat pantau elektrokardiografi (EKG), tekanan darah noninvasif, serta pulse oxymetri, kemudian dicatat data tekanan darah sistol, diastol dan tekanan darah rata-rata, laju nadi, laju napas, dan juga saturasi oksigen. Setelah pasien diposisikan duduk, dilakukan tindakan a dan antisepsis dengan larutan povidon iodin serta alkohol $70 \%$ pada tempat penyuntikan epidural yang kemudian dilanjutkan dengan infiltrasi lidokain $2 \%$, sesaat setelah dilakukan infiltrasi dengan lidokain $\mathrm{HCl} 2 \%$ ditanyakan kepada pasien apakah merasakan nyeri, yang dinilai dengan menggunakan NRS, kemudian dicatat oleh penilai.

\section{Hasil}

Hasil analisis statistika menunjukkan bahwa karakteristik umum subjek penelitian, yaitu usia, jenis kelamin, pendidikan, dan juga status fisik American Society of Anesthesiologist (ASA) pada kelompok lidokain yang dialkalinisasi maupun dialkalinisasi tidak berbeda bermakna ( $p>0,05$; Tabel 1).

Tabel 1 Karakteristik Umum Subjek Penelitian Kelompok Lidokain dan Lidokain Alkalinisasi

\begin{tabular}{lccc}
\hline \multirow{2}{*}{ Karakteristik } & \multicolumn{2}{c}{ Kelompok } & \multirow{2}{*}{ Nilai p } \\
\cline { 2 - 3 } & L (n=22) & LB (n=22) & 0,844 \\
\hline Usia (tahun) & $42,41(13,53)$ & $41,59(13,82)$ & \\
$\quad$ Rata-rata (SD) & & & 1,000 \\
Jenis kelamin & 14 & 14 & \\
Pria & 8 & 8 & 0,272 \\
Wanita & & & \\
Pendidikan & 2 & 2 & \\
SD & 1 & 2 & \\
SMP & 9 & 12 & 0,332 \\
SMA & 10 & 6 & \\
S1 & & & \\
ASA & 13 & 17 & \\
I & 9 & 5 & \\
II & & & \\
\hline
\end{tabular}

Keterangan: nilai p pada variabel usia dihitung berdasarkan uji-t tidak berpasangan. Nilai p pada variabel Jenis kelamin dan ASA dihitung berdasarkan uji chi-kuadrat dan nilai p pada variabel pendidikan dihitung berdasarkan Uji Mann-Whitney. Nilai p bermakna jika p<0,05 
Tabel 2 Perbandingan Tingkat Kecemasan dan Derajat Nyeri pada Kedua Kelompok Perlakuan

\begin{tabular}{lccc}
\hline & \multicolumn{2}{c}{ Kelompok } & \multirow{2}{*}{ Nilai p } \\
\cline { 2 - 3 } & L (n=22) & LB (n=22) & \\
\hline Tingkat Kecemasan & 13 & & \multirow{2}{*}{0,366} \\
Tidak cemas & 9 & 13 & \\
$\quad$ Ringan & & & \multirow{2}{*}{$0,000^{*}$} \\
Derajat Nyeri & 2 & 19 & \\
$\quad$ Ringan & 20 & 3 & \\
Sedang & & 9 & \\
\hline
\end{tabular}

Keterangan: nilai p dihitung berdasarkan uji chi-kuadrat. Nilai $p$ bermakna jika $p<0,05$

Hasil pengukuran tingkat kecemasan pada kedua kelompok sebagian besar menunjukkan tingkat cemas yang ringan dan tidak ditemukan gejala cemas sedang ataupun berat. Perbedaan proporsi kategori cemas pada kedua kelompok dinyatakan tidak bermakna ( $\mathrm{p}>0,05)$.

Saat dilakukan tindakan infiltrasi, mayoritas subjek pada kelompok lidokain ini mengalami nyeri skala sedang, sedangkan pada kelompok lidokain yang dialkalinisasi mayoritas subjek penelitian mengalami nyeri ringan. Perbedaan proporsi derajat nyeri pada kedua kelompok dinyatakan bermakna ( $\mathrm{p}<0,05$; Tabel 2).

Berdasarkan penilaian numeric rating scale (NRS), diperoleh hasil analisis perbandingan skor NRS dengan menggunakan median dan rentang. Pada saat infiltrasi, pada kelompok lidokain diperoleh nilai median NRS sebesar 5 dengan rentang nilai NRS berkisar pada 3-6. Pada kelompok lidokain yang dialkalinisasi, diperoleh nilai median NRS sebesar 3 (lebih rendah) serta rentang nilai NRS berkisar 1-4. Perbedaan median NRS pada kedua kelompok perlakuan tersebut dinyatakan bermakna $(\mathrm{p}<$
0,05).

Berdasarkan hasil analisis, diketahui bahwa hanya ditemukan dua subjek penelitian yang mendapatkan tambahan anestetik lokal pada kelompok lidokain, pada kelompok lidokain yang dialkalinisasi tidak terdapat seorangpun yang mendapatkan tambahan anestetik lokal dengan perbedaan tidak bermakna $(p>0,05)$.

Hasil pengujian statistika memperlihatkan bahwa tekanan darah sistol kedua kelompok tidak menunjukkan perbedaan bermakna baik saat awal, maupun saat infiltrasi ( $p>0,05$; Tabel 3). Pengukuran tekanan darah diastol kedua kelompok juga tidak menunjukkan perbedaan yang bermakna baik saat awal, saat infiltrasi, maupun saat insersi $(p>0,05)$.

Laju napas serta nadi pada saat sebelum penyuntikan tidak menunjukkan perbedaan bermakna antara kedua kelompok $(p>0,05)$. Laju nadi pada saat infiltrasi dan saat insersi menunjukkan bahwa laju nadi pada kelompok lidokain lebih tinggi dengan perbedaan yang bermakna $(p<0,05)$.

Tabel 3 Perbandingan Tekanan Darah Sistol antara Kelompok Lidokain dan Lidokain Alkalinisasi

\begin{tabular}{lccc}
\hline \multirow{2}{*}{ Waktu Pengukuran } & \multicolumn{2}{c}{ Kelompok } & \multirow{2}{*}{ Nilai p } \\
\cline { 2 - 3 } & $\mathbf{L ~ ( n = 2 2 )}$ & LB (n=22) & \\
\hline Sebelum dilakukan infiltrasi (mmHg, SB) & $132,27(13,52)$ & $132,68(13,37)$ & 0,920 \\
Saat dilakukan infiltrasi (mmHg, SB) & $133,86(8,6)$ & $131,95(14,2)$ & 0,593 \\
\hline
\end{tabular}

Keterangan: nilai $p$ dihitung berdasarkan uji-t tidak berpasangan. Nilai p bermakna jika $p<0,05$ 
Tabel 4 Perbandingan Tekanan Darah Diastol antara Kelompok Lidokain dan Lidokain Alkalinisasi

\begin{tabular}{lccc}
\hline \multirow{2}{*}{ Waktu Pengukuran } & \multicolumn{2}{c}{ Kelompok } & \multirow{2}{*}{ Nilai p } \\
\cline { 2 - 3 } & L (n=22) & LB (n=22) & \\
\hline Sebelum dilakukan infiltrasi (mmHg, SB) & $78,64(7,74)$ & $79,14(7,98)$ & 0,834 \\
Saat dilakukan Infiltrasi (mmHg, SB) & $78,09(7,72)$ & $75,36(8,84)$ & 0,282 \\
\hline
\end{tabular}

Keterangan: nilai p dihitung berdasarkan uji-t tidak berpasangan. Nilai p bermakna jika $p<0,05$

\section{Pembahasan}

Teknik anestesia epidural merupakan salah satu anestesia regional yang dapat dikerjakan untuk memfasilitasi proses pembedahan dan memberikan keuntungan dalam pengelolaan nyeri pascabedah. Nyeri pada saat dilakukan penusukan jarum epidural merupakan salah satu hal yang paling mengganggu kenyamanan pasien. Hal tersebut diatasi dengan pemberian anestesi infiltrasi di daerah penyuntikan jarum epidural dengan menggunakan obat anestesia lokal. ${ }^{8}$

Pada hasil penelitian terdahulu didapatkan nilai VAS 7 pada saat dilakukan infiltrasi obat anestesi lokal lidokain 2\%, hal tersebut dapat disebabkan $\mathrm{pH}$ obat anestesi lokal yang asam menyebabkan iritasi pada jaringan sehingga menimbulkan sensasi panas serta nyeri. Pada nilai $\mathrm{pH}$ yang rendah fraksi nonionisasi anestesi lokal juga rendah sehingga mula kerja anestetik lokal lebih lama. Selain efek pH obat, ukuran jarum, suhu, dan kecepatan penyuntikan obat anestesi lokal juga memengaruhi nyeri yang ditimbulkan saat infiltrasi anestesi lokal. ${ }^{4,5,9}$

Nakayama dkk. ${ }^{7}$ telah menyatakan bahwa tindakan alkalinisasi pada lidokain $\mathrm{HCl}$ dengan cara menambahkan natrium bikarbonat $8,4 \%$ dengan perbandingan pengenceran 1:10 akan mengubah $\mathrm{pH}$ mendekati $\mathrm{pH}$ jaringan tubuh tanpa risiko terjadinya presipitasi pada obat anestesi lokal serta lebih stabil. Pada penelitian lain mempergunakan alkalinisasi lidokain $\mathrm{HCl}$ 2\% dengan pengenceran 1:2 dan 1:5 untuk nyeri pada saat infiltrasi anestetik lokal tidak menunjukkan hasil yang signifikan untuk mengurangi nyeri saat infiltrasi anestetik lokal dibandingkan dengan tanpa alkalinisasi. ${ }^{6,7,10}$
Data karakteristik umum subjek penelitian, baik pada kelompok eksperimen (LB) maupun kelompok kontrol (L) tidak berbeda baik jenis kelamin, usia, dan juga tingkat pendidikan, sehingga kedua kelompok dianggap homogen dan layak dibandingkan. Sebaran yang cukup merata pada jenis kelamin, usia, dan tingkat pendidikan pada kedua kelompok diharapkan dapat memperkecil bias yang mungkin timbul dalam persepsi nyeri pada pasien.

Secara umum faktor kecemasan merupakan salah satu faktor yang memengaruhi persepsi seseorangtentang nyeri.Padapenelitian inijuga dilakukan upaya untuk menghomogenisasikan persepsi subjek tentang nyeri, oleh sebab itu dilakukan penilaian tingkat nyeri dengan cara mempergunakan skala HARS dan didapatkan hasil kecemasan preoperatif kedua kelompok secara statistika tidak didapat perbedaan yang bermakna $(p>0,05)$. Hasil pengukuran tersebut menunjukkan bahwa tingkat kecemasan pada kedua kelompok adalah homogen sehingga kedua kelompok layak untuk diperbandingkan.

Pasien pada kelompok lidokain alkalinisasi yang merasakan nyeri derajat ringan berjumlah 19/22 orang pasien, sedangkan pada kelompok lidokain hanya 2/20 pasien (Tabel 2). Hal ini mendukung penelitian sebelumnya, bahwa alkalinisasi lidokain $\mathrm{HCl}$ 2\% mengurangi nyeri walaupun pada 2 penelitian sebelumnya tidak diketahui jumlah atau persentase pasien yang mengalami nyeri sedang sampai berat. ${ }^{6,7}$

Alkalinisasi anestesi lokal akan mengurangi intensitas nyeri yang diakibatkan oleh infiltrasi anestetik lokal. Nyeri yang ditimbulkan akibat infiltrasi zat anestetik lokal disebabkan karena $\mathrm{pH}$ sediaan obat anestesia lokal bersifat asam, terutama sediaan yang mengandung epinefrin. 
Hal tersebut bertujuan untuk preservasi obat anestesia lokal agar tetap dalam keadaan yang stabil, terutama yang mengandung epinefrin. Seberapa banyak natrium bikarbonat dapat ditambahkan ke dalam anestetik lokal tidak terdapat patokan yang pasti, namun pada dosis yang sering dipakai telah dapat meningkatkan pH solusi mendekati $\mathrm{pH}$ jaringan. ${ }^{4,5,11,12}$

Semua data pada penelitian menunjukkan efek alkalinisasi lidokain $\mathrm{HCl} 2 \%$ bermakna untuk mengurangi nyeri saat infiltrasi serta saat insersi jarum epidural. Hal ini disebabkan peningkatan nilai $\mathrm{pH}$ dari lidokain $\mathrm{HCl} 2 \%$ yang dialkalinisasi sehingga mendekati $\mathrm{pH}$ tubuh. Peningkatan $\mathrm{pH}$ ini bukan saja meningkatkan mula kerja obat tetapi juga akan meningkatkan efikasi dan intensitas blok saraf., ${ }^{9,13}$

\section{Simpulan}

Simpulan penelitian ini adalah penambahan larutan natrium bikarbonat $8,4 \%$ ke dalam lidokain $\mathrm{HCl} 2 \%$ dengan perbandingan 1:10 dapat mengurangi nyeri pada saat infiltrasi anestetik lokal dengan nilai NRS yang lebih rendah pada kelompok lidokain alkalinisasi.

\section{Daftar Pustaka}

1. Stephen BW, Mcguik TD. Subcutaneous buffered lidocaine for intravenous cannulation: is there a role in emergency medicine. Academic Emergency Med. 1998;5:1057-63.

2. Younis I, Bhutiani RP. Taking the 'ouch' out-effect of buffering commercial xylocaine on infiltration and procedure pain-a prospective, randomised, doubleblind, controlled trial. Ann R Coll Surg Engl. 2004;86:213-7.

3. Bernard C. Epidural and spinal anestesia. Dalam: Barash P, Cullen B, Stoelting R, penyunting. Clinical anestesia. Edisi ke-5. Philadelphia: Lippincott Williams and Wilkins; 2006. hlm. 692-718.
4. Morison D. Alkalinization of local anaesthetics. Can J Anesth. 1995;42:10769.

5. Davies R. Buffering the pain of local anaesthetics a systematic review. Emerg Med. 2003;15:81-8.

6. Burns C, Ferris G, Feng C, Cooper J, Brown. Decreasing the pain of local anesthesia: a prospective, double-blind comparison of buffered, premixed 1\% lidokaine with epinephrine versus $1 \%$ lidokaine freshly mixed with epinephrine. J Am Acad Dermatol. 2006;54:128-31.

7. Nakayama M, Munemura $Y$, Kanaya $\mathrm{N}$, Tsuchida H, Namiki A. Efficacy of alkalinized lidokaine for reducing pain on intravenous and epidural catheterization. J Anesthesia. 2001;15:201-3.

8. Kleinmann W. Spinal, epidural, and caudal blocks. Dalam: Morgan GE, penyunting. Clinical anesthesiology. Edisi ke-4. Los Angeles: McGraw-Hill.; 2006. hlm. 289323.

9. Yiannakopoulos C. Carpal ligament decompression under local anaesthesia: the effect of lidocaine warming and alkalinisation on infiltration pain. J Hand Surg. 2004;29B:32-4.

10. Al-Sultan FA, Fathie WK, Hamid RS. A clinical evaluation on the alkalization of local anesthetic solution in periapical surgery. Al-Rafidain Dent J. 2006;6:71-7.

11. Curatolo M, Felix SP, Nielsen LA, Lauber R, Hogstrom H, Scaramozzino P, dkk. Adding sodium bicarbonat to lidocaine enhance the depth of epidural blockade. Anesth Analg. 1998;86:341-7.

12. Stoelting R, Hillier S. Local anesthetics. Dalam: Stoelting RK, penyunting. Pharmacology and physiology in anesthetic practice. Edisi ke-3. Philadelphia: Lippincott Williams \& Wilkins; 2006. hlm. 179-203.

13. CooperD,SeupaulR. Doesbufferedlidocaine decrease the pain of local infiltration? Ann Emerg Med. 2012;59:281-2. 